\title{
Cardiopulmonary bypass in the young
}

\author{
Ross M. Ungerleider, William J. Greeley and Richard A. Jonas
}

$\mathrm{T}$ HIS ISSUE OF CARDIOLOGY IN THE YOUNG INCLUDES A special section devoted to cardiopulmonary bypass and how it affects the young patient. It seems appropriate that these matters are addressed in an issue that coincides with the World Congress of Pediatric Cardiology and Cardiac Surgery. At the First World Congress of Pediatric Cardiac Surgery, held in Bergamo in 1988, Kirklin used his presidential address to discuss the "movement of cardiac surgery towards the very young." "This "movement" has been expedited since then by the ability of many groups to achieve impressive results in the early correction of a variety of congenital heart defects, and has led to major shifts in philosophy regarding the value of palliation in otherwise correctable defects in the small patient. Now, in 1993, enthusiasm has increased for early one-stage repair, without prior palliation, for correctable congenital heart disease, and neonatal heart surgery seems to be an evolving practice within the subspecialty of congenital heart surgery. The result is that an increasing number of young patients are being exposed to cardiopulmonary bypass and are "at risk" for damaging effects from the very same technology that has opened the vista of early infant repair.

Because of their small size (compared to adults), neonates and infants have a disproportionate exposure to the nonendothelialized surface of cardiopulmonary bypass, potentially exaggerating its deleterious effects. Moreover, the physiologic extremes during cardiopulmonary bypass are more pronounced in infants than in adults. These include deep hypothermic temperatures $\left(15-18{ }^{\circ} \mathrm{C}\right)$, periods of low flow or even no perfusion (total circulatory arrest), and low mean arterial pressures (20-30 mm Hg). Despite these potential disadvantages, cardiopulmonary bypass is becoming much safer in the young patient due to our improved understanding of its effects. The work presented in this section of the Journal underscores the tremendous strides made in our understanding, in recent years, of the effects of cardiopulmonary bypass and circulatory arrest in the young patient.
The first group of manuscripts address the response to cardiopulmonary bypass. In the first article, Lazenby et $\mathrm{al}^{2}$ provide an overview of the effects of cardiopulmonary bypass on various organs with reference to blood flow and metabolism. They note the important differences between normothermic and hypothermic cardiopulmonary bypass. The article by Finn and Dreyer ${ }^{3}$ provides a thorough overview of the impact of cardiopulmonary bypass on the mechanisms for immune defense. The inflammatory response that follows cardiopulmonary bypass can result in varying degrees of injury to tissues and visceral dysfunction which are mediated by activation of complement and neutrophils. Finn and Dreyer $^{3}$ raise the intriguing possibility that, as we learn more about ways to modulate the response of the immune system to exposure to cardiopulmonary bypass, we may be able to eliminate some of the undesirable responses to cardiopulmonary bypass that negatively affect our results.

Edmunds ${ }^{4}$ presents a comprehensive review of the hemostatic changes associated with cardiopulmonary bypass. He emphasizes the effects of contact of blood with the nonendothelialized surface of cardiopulmonary bypass stimulating the cells within the blood itself, as well as the so-called "contact system" of plasma proteins. Dietrich et al ${ }^{5}$ discuss one of the most perturbing problems of cardiopulmonary bypass-anticoagulation and postoperative bleeding. They address new pharmacologic therapies such as the use of aprotinin, which has enormous potential for reducing postoperative bleeding. Taken together, these articles ${ }^{4.5}$ provide an authoritative review of the impact of cardiopulmonary bypass on coagulation.

The final manuscript in this section, by Hanley, ${ }^{6}$ addresses fetal cardiopulmonary bypass. This intriguing article provides a window for the furure by elaborating on the experimentally observed consequences of cardiopulmonary bypass on the fetus and on placental circulation. As cardiac surgery continues to move "toward the young," this technique may provide access to a new population of patients. 
The next group of manuscripts discusses the effects of cardiopulmonary bypass and circulatory arrest on the developing brain. With increasing improvement in surgical results for repair in early infancy, it is now necessary to focus on long-term quality of life. Because of the concern that deep hyporhermic cardiopulmonary bypass with low pump flow rates or total circulatory arrest may injure the developing brain, several groups have examined these techniques in more detail. The mechanisms of hypothermic protection, as well as the effect of regulation of blood gases during cardiopulmonary bypass, are elegantly discussed by Hindman. ${ }^{7}$ The potential deleterious effect of total circulatory arrest on changes in regional cerebral blood flow, cerebral metabolism, and extraction of oxygen are the subject of the manuscript by Tam et al. ${ }^{8}$ Mezrow et al ${ }^{9}$ review the concept of the vulnerability of the brain to ischemia due to hemodynamic instability after circulatory arrest. In companion articles, the group from Boston discuss their experimental investigations of cardiopulmonary bypass under low flow and circulatory arrest using nuclear magnetic resonance spectroscopy ${ }^{10}$ and correlate these findings with their clinical studies concerning neuropsychologic outcome. ${ }^{11}$ In the final manuscript, Greeley et al $^{12}$ address strategies for cerebral protection in the young patient using both experimental and clinical data. As a composite, these manuscripts represent an excellent up-to-date compendium regarding the cerebral response of the young patient to cardiopulmonary bypass. They also provide insight into how neuropsychologic outcome might be improved.

The subsequent issue of Cardiology in the Young will carry the concluding articles in this special series. These will include a section on techniques used for cardiopulmonary bypass featuring contributions from two European groups (Naik and Elliott from Hospital for Sick Children, London, and Lacour-Gayet from Marie Lannelongue, Paris) describing effective techniques for conservation of blood and management of fluids after cardiopulmonary bypass that may have advantageous effects on myocardial and pulmonary function. ${ }^{13,14} \mathrm{Al}$ though this is an area of much active research, these articles will serve to bring the reader up to date on a potentially important technique in future strategies for cardiopulmonary bypass. The subsequent articles presented by Habbal and Elliott ${ }^{15}$ and by Groom et al ${ }^{16}$ demonstrate the marked variability in Europe and in the United States (respectively) between currently employed techniques for cardiopulmonary bypass. Both reviews demonstrate remarkable similarities with reference to operative techniques; but the differences in techniques such as management of blood gases, rates of flow through the pump, temperatures within the circuit used for cardiopulmonary bypass, use of cardioplegia, and constituents of the prime are remarkable. These variations in techniques probably represent areas where standards of care are yet to be established by careful collection of data. They define topics deserving of further investigation. An article by Jobes et al ${ }^{17}$ will summarize specific issues relating to coagulation in the young patient, and research by Ekroth et $\mathrm{al}^{18}$ and by Wantanabe et al $^{19}$ will complete topics relating to cerebral protection by focusing on pulsatile perfusion and on strategies for rewarming respectively. The series will be concluded by a review by Auten ${ }^{20}$ summarizing the characteristics in maturation of organs which distinguish the young from the older patient-changes which potentially influence the management of cardiopulmonary bypass.

The articles contained in this special section of Cardiology in the Young provide the reader with a timely syllabus of the effects of cardiopulmonary bypass on the young patient. They reflect the truly multidisciplinary nature of the treatment of congenital heart disease. The information has been contributed by physicians from a variety of specialties-all sharing a common interest in treatment of heart disease in the young. With continuing improvement in diagnostic and surgical capabilities, as well as with improvements in management of cardiopulmonary bypass (hopefully stimulated in part by the thoughts provoked by this special series) the outlook for infants born with congenital heart defects will continue to improve.

\section{Departments of Surgery and Anesthesiology Duke Children's Hospital \\ Duke Medical Center \\ Durham, NC 27710, USA}

Department of Cardiac Surgery

Children's Hospital

300 Longwood Avenue

Boston, MA 02115, USA

\section{References}

1. Kirklin JW. The movement of cardiac surgery to the very young. In: Crupi G, Parenzan L, Anderson RH (eds). Perspectives in Pediatric Cardiology, Volume 2, Pediatric Cardiac Surgery, Part 1. Futura Publishing Company, Inc., Mount Kisco, NY, 1989, pp 3-20.

2. Lazenby WD Jr, Krieger KH. Cardiopulmonary bypassflow of blood to the organs and metabolism in children. Cardiol Young 1993; 3: 232-243.

3. Finn A, Dreyer WJ. Neutrophil adhesion and the inflammatory response induced by cardiopulmonary bypass. Cardiol Young 1993; 3: 244-250.

4. Edmunds LH Jr. Effects of cardiopulmonary bypass on the coagulation system. Cardiol Young 1993; 3: 251-256.

5. Dietrich W, Mössinger HJ, Richter JA. Treatment of bleeding following cardiopulmonary bypass in neonates and infants. Cardiol Young 1993; 3: 257-262. 
6. Hanley FL. Fetal responses to extracorporeal circulatory support. Cardiol Young 1993; 3: 263-272.

7. Hindman BJ. Cerebral physiology of hypothermia and hypothermic acid-base management during cardiopulmonary bypass. Cardiol Young 1993; 3: 273-280.

8. Tam VKH, Cameron DE. Cerebral blood flow following hypothermic circulatory arrest. Cardiol Young 1993; 3: 281286.

9. Mezrow CK, Midulla P, Sadeghi AM, Dapunt O, Gandsas A, Shiang $\mathrm{H}$, D'Alessandro DA, Griepp RB. A vulnerable interval for cerebral injury-comparison of hypothermic circulatory arrest and low flow cardiopulmonary bypass. Cardiol Young 1993; 3: 287-298.

10. Jonas RA. Experimental studies of hypothermic circulatory arrest and bypass with low flow. Cardiol Young 1993; 3: 299307

11. Wernovsky G, Jonas RA, Hickey PR, du Plessis AJ, Newburger JW. Clinical neurologic and developmental studies after cardiac surgery utilizing hypothermic circulatory arrest and cardiopulmonary bypass. Cardiol Young 1993; 3: 308-316.

12. Greeley WJ, Kern FH, Mault JR, Skaryak LA, Ungerleider RM. Mechanisms of injury and methods of brain protection during neonatal and infant cardiac surgery. Cardiol Young
1993; 3: 317-330

13. Naik K, Elliott MJ. Ultrafiltration and pediatric cardiopulmonary bypass. Cardiol Young 1993; 3: 331-339.

14. Lacour-Gayet F, Nicolas F, Coll J, Daniel JP, Weiss M, Pelissie $\mathrm{J}$, Bruniaux J, Planché C. Continuous perfusion without hemodilution in neonates-the experience at the Marie Lannelongue Hospital. Cardiol Young 1993; 3: 340-346.

15. El Habbal MH, Elliott MJ. European approach for cardiopulmonary bypass in neonates. Cardiol Young 1993; 3: 347-352.

16. Groom RC, Hill AG, Akl B, Kurusz M, Lefrak EA. Neonatal cardiopulmonary bypass-a review of current practice in North America. Cardiol Young 1993; 3: 353-369.

17. Jobes DR, Nicolson SC, Steven JM. Inhibition and restoration of hemostasis in the young patient. Cardiol Young 1993; 3: 370-377.

18. Ekroth R, van der Linden J, Lincoln C, Scallan M. Cerebral perfusion and metabolism after profound hypothermiacomparison between procedures involving no flow and low flow. Cardiol Young 1993; 3: 378-382.

19. Wantanabe T, Washio M. Cerebral cellular response to profound hypothermia. Cardiol Young 1993; 3: 383-393.

20. Auten RL Jr. The impact of cardiopulmonary bypass in the developing patient. Cardiol Young 1993; 3: 394-406. 


\section{didece}

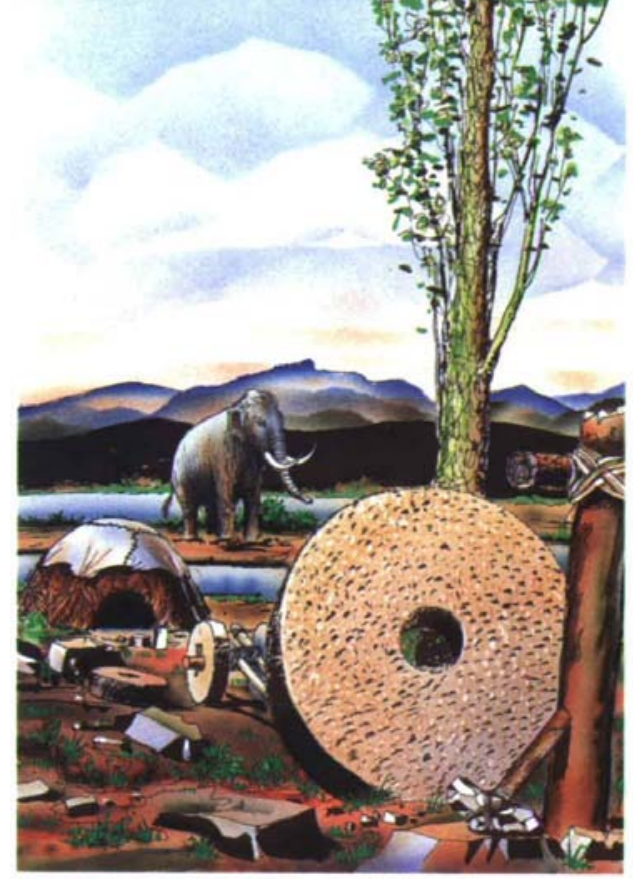

\section{A PASSION FOR TOP PERFORMANCE ...}

Created for the users who demand highest safety and top performance, Masterflo 34 and Masterflo 51 are hollow fibre oxygenators representing a true technical innovation in neonatal and paediatric cardiopulmonary bypass. The closed system design offers a simple and effective degree of safety against massive air embolism. Blood flow is controlled

by a single pump.

Masterflo 34 can process a maximum blood flow of $1.51 / \mathrm{min}$ whereas Masterflo 51 has a maximum blood flow of $2.5 \mathrm{l} / \mathrm{min}$.

The Masterflo series incorporates a $215 \mathrm{mls}$ venous bag reservoir with integrated bubble trap.

Venous blood is gravity drained into the reservoir bag and pumped to the heat exchanger/hollow fibre oxygenator structure.

The blood path is outside and around the microporous fibres while the gas path is through the lumen of the fibre itself.

DIDECO S.p.A. 41037 MIRANDOLA (MO) - Italy Via Statale 12 Nord, $86 \cdot$ P.O. Box 87 Tel. 39/535/29811 - Tlx 522388 Fax 39/535/25229
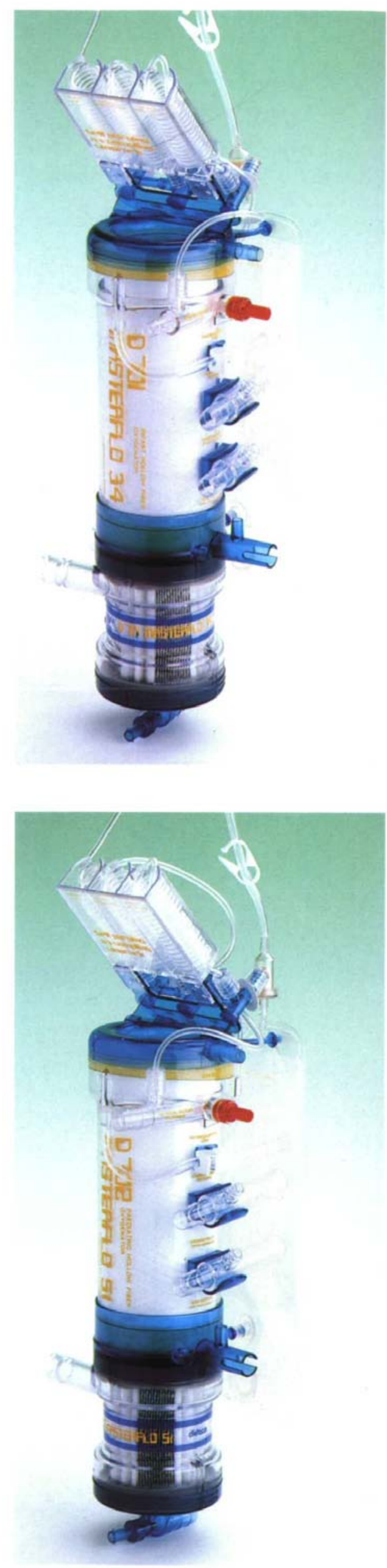


\section{705 MIDIFLO}

System

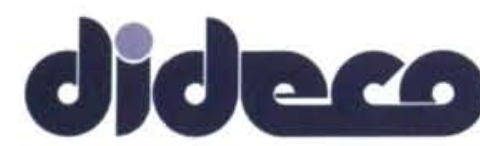

DIDECO S.P.A.

41037 MIRANDOLA (MO) - Italy

Via Statale 12 Nord, 86 - P.O. Box 87

Tel. 39/535/29811 - Tlx 522388

Fax 39/535/25229

\section{It's small... but it thinks big.}

Introducing the new Dideco D 705 Midiflo System. The D 705 Midiflo paediatric hollow fibre oxygenator can do so much it's almost unfair to call it a «small» oxygenator. It offers many advantages in performance, which makes it an ideal choice for a wide range of paediatric/small-adult patients with blood flow requirements up to $4.0 \mathrm{l} / \mathrm{min}$ (4.5 $\mathrm{l} / \mathrm{min}$ A.A.M.I. standards).
The concept of the self closing valve placed in the integrated venous/cardiotomy reservoir provides the ideal operating characteristics. The practicality of the open system combined with the safety expected from a closed one.

It's small in priming: $140 \mathrm{mls}$.

It's big in versatility and ease of use. 